\title{
Åland island eye disease: clinical and electrophysiological studies of a Welsh family
}

\author{
N R Hawksworth, S Headland, P Good, N S T Thomas, A Clarke
}

\begin{abstract}
Clinical and molecular genetic studies were performed on a single, large, white family, in which congenital nystagmus and moderate to high refractive error segregated as a sex linked trait with manifestation in some female carriers. In this family, affected males demonstrate myopia, but a high proportion of female carriers, and some of the possibly affected males, show hypermetropia. Clinical ophthalmic examination and electrodiagnostic studies of retinal function were fully compatible with a diagnosis of either incomplete congenital stationary night blindness or of Ảland island eye disease. Previous studies have mapped both disorders to the proximal short arm of the $X$ chromosome: our molecular studies support this localisation. Incomplete congenital stationary nightblindness and Aland Island eye disease could be considered as a single entity.

(Br F Ophthalmol 1995; 79: 424-430)
\end{abstract}

Numerous eye diseases include nystagmus as an important part of their clinical picture and are inherited in an $\mathrm{X}$ linked manner. Most could be excluded readily from the differential diagnosis by the clinical findings of the probands. The diagnosis for our family was either type 2 ocular albinism (Åland Island eye disease), or the incomplete form of congenital stationary nightblindness.

\section{ÅLAND ISLAND EYE DISEASE (AIED)} (FORSIUS-ERIKSSON SYNDROME, OR TYPE 2 OCULAR ALBINISM)

Forsius and Eriksson described an X linked condition in a large family in $1964 .^{1}$ There have been other reports since. ${ }^{2}$ Affected males have reduced visual acuity, mild red-green colour blindness, and axial myopia (ranging from -3.00 to $-18.00 \mathrm{DS}$ ) with astigmatism. Nystagmus is usually present, though two males in Rosenberg's series ${ }^{2}$ had high myopia but no nystagmus. Female carriers may exhibit latent nystagmus and there may be an increased degree of myopia. There is usually a history of nightblindness. Fundus examination shows foveal hypoplasia and fundus hypopigmentation. There are similarities to type 1 ocular albinism, ${ }^{3}$ but there is no misrouting of the optic nerve fibres in AIED. ${ }^{4}$ Evidence for misrouting in type 1 ocular albinism ${ }^{5}$ is seen on visual evoked potentials (VER).
Department of Ophthalmology, University Hospital of Wales, Cardiff

N R Hawksworth

\section{Department of}

Medical Genetics,

University Hospital of

Wales, Cardiff

$S$ Headland

N S T Thomas

A Clarke

Birmingham and Midland Eye Hospital, Birmingham

P Good

Correspondence to: Mr N R Hawksworth, Department of Department of Ophthalmology, Eas Glamorgan General Hospital, Church Village, Pontypridd CF38 1AB.

Accepted for publication 9 January 1995

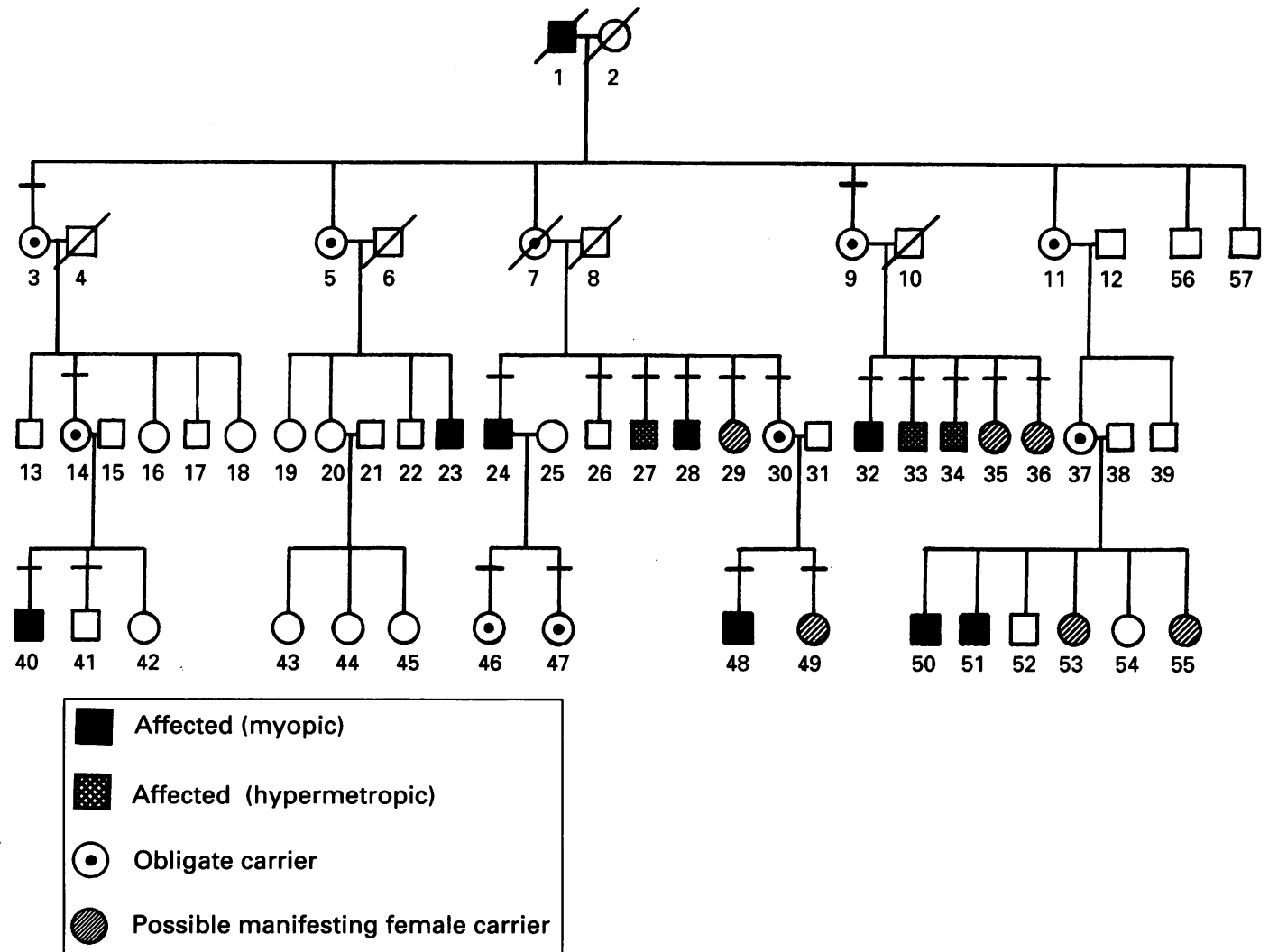

Figure 1 Pedigree of kindred demonstrating $X$ linked condition. The patients examined are indicated by a horizontal bar. 


\begin{tabular}{|c|c|c|c|c|c|c|c|c|c|c|c|c|c|}
\hline \multirow[b]{2}{*}{ No } & \multirow[b]{2}{*}{$\begin{array}{l}\text { Age } \\
\text { (years) }\end{array}$} & \multirow[b]{2}{*}{ Nightblindness } & \multirow[b]{2}{*}{ Photophobia } & \multicolumn{2}{|c|}{ Visual acuity } & \multicolumn{2}{|l|}{ Refraction } & \multirow[b]{2}{*}{ Strabismus } & \multirow[b]{2}{*}{ Amblyopia } & \multirow[b]{2}{*}{ Nystagmus } & \multirow[b]{2}{*}{$\begin{array}{l}\text { Colour } \\
\text { vision }\end{array}$} & \multirow[b]{2}{*}{ Pigment } & \multirow[b]{2}{*}{$\begin{array}{l}\text { Disc } \\
\text { anomaly }\end{array}$} \\
\hline & & & & Right & Left & $\begin{array}{l}\text { Right } \\
\text { (dioptres) }\end{array}$ & $\begin{array}{l}\text { Left } \\
\text { (dioptres) }\end{array}$ & & & & & & \\
\hline \multicolumn{14}{|c|}{ Males: definitely affected: } \\
\hline 24 & 41 & - & - & $6 / 36$ & $6 / 36$ & $-6 \cdot 50$ & $-6 \cdot 00$ & RtCS & - & Yes & Poor & - & Yes \\
\hline 32 & 39 & Yes & Yes & $6 / 24$ & $6 / 24$ & $-3 \cdot 50$ & $-4 \cdot 50$ & - & - & Yes & Poor & - & Yes \\
\hline 40 & 22 & Yes & - & $6 / 12$ & $6 / 12$ & $-7 \cdot 25$ & $-7 \cdot 25$ & - & - & Yes & - & $\mathrm{V}$ pale & Yes \\
\hline 48 & 4 & - & - & $6 / 18$ & $6 / 18$ & -3.00 & $-3 \cdot 00$ & - & - & Yes & - & Pale & \\
\hline 28 & 32 & - & - & $6 / 9$ & $6 / 12$ & $-18 \cdot 00$ & $-18 \cdot 00$ & - & - & - & - & Pale & Yes \\
\hline 26 & 38 & - & - & $6 / 5$ & $6 / 5$ & 0.00 & 0.00 & - & - & - & - & - & - \\
\hline 27 & 35 & - & Yes & $6 / 6$ & $6 / 6$ & $+1 \cdot 50$ & +1.50 & $\overline{-}$ & - & - & - & - & $\bar{v}$ \\
\hline 33 & 32 & - & Yes & $6 / 9$ & $6 / 9$ & $+2 \cdot 50$ & $+2 \cdot 25$ & RtCS & - & - & - & - & Yes \\
\hline 34 & 28 & - & Yes & $6 / 9$ & $6 / 9$ & $+4 \cdot 50$ & $+5 \cdot 00$ & - & - & - & - & - & - \\
\hline 41 & 20 & - & - & $6 / 4$ & $6 / 4$ & 0.00 & 0.00 & - & - & - & - & - & - \\
\hline \multicolumn{14}{|c|}{ Females: obligate carriers: } \\
\hline 3 & 73 & - & - & $6 / 9$ & $6 / 9$ & $+2 \cdot 25$ & +3.00 & - & - & - & - & - & - \\
\hline 9 & 63 & - & - & $6 / 12$ & $6 / 6$ & $+4 \cdot 00$ & $+1 \cdot 25$ & - & Yes & - & - & - & - \\
\hline 14 & 44 & Yes & - & $6 / 60$ & $6 / 60$ & $\begin{array}{l}-4.45 / \\
+4 \mathrm{DC} 90\end{array}$ & $\begin{array}{l}-6 \cdot 50 / \\
+4 \mathrm{DC} 75\end{array}$ & - & - & Yes & - & Pale & - \\
\hline 30 & 30 & - & - & $6 / 18$ & $6 / 6$ & $+6 \cdot 00$ & $+6 \cdot 00$ & RtCS & Yes & - & - & - & Yes \\
\hline 47 & 17 & - & - & $6 / 18$ & $6 / 5$ & $+9 \cdot 00$ & $+3 \cdot 00$ & RtCS & Yes & - & - & - & Yes \\
\hline \multicolumn{14}{|c|}{ Females: uncertain status: } \\
\hline 29 & 27 & - & - & $6 / 5$ & $\mathrm{CF}$ & $-1 \cdot 75$ & $\begin{array}{l}+4 \cdot 50 / \\
+2 \mathrm{DC} 85\end{array}$ & - & Yes & - & - & - & - \\
\hline 35 & 37 & - & - & $6 / 5$ & $6 / 5$ & $+4 \cdot 00$ & $+6 \cdot 00$ & AlCS & - & - & - & - & - \\
\hline 36 & 26 & - & - & $6 / 5$ & $6 / 12$ & 0.00 & $+6 \cdot 00$ & $\overline{-}$ & Yes & - & - & - & - \\
\hline 49 & 10 & - & - & $6 / 60$ & $6 / 6$ & +3.00 & $+2 \cdot 50$ & RtDS & Yes & - & - & - & - \\
\hline
\end{tabular}

RtCS = Right convergent squint; AlCS=Alternating convergent squint; RtDS= Right divergent squint.
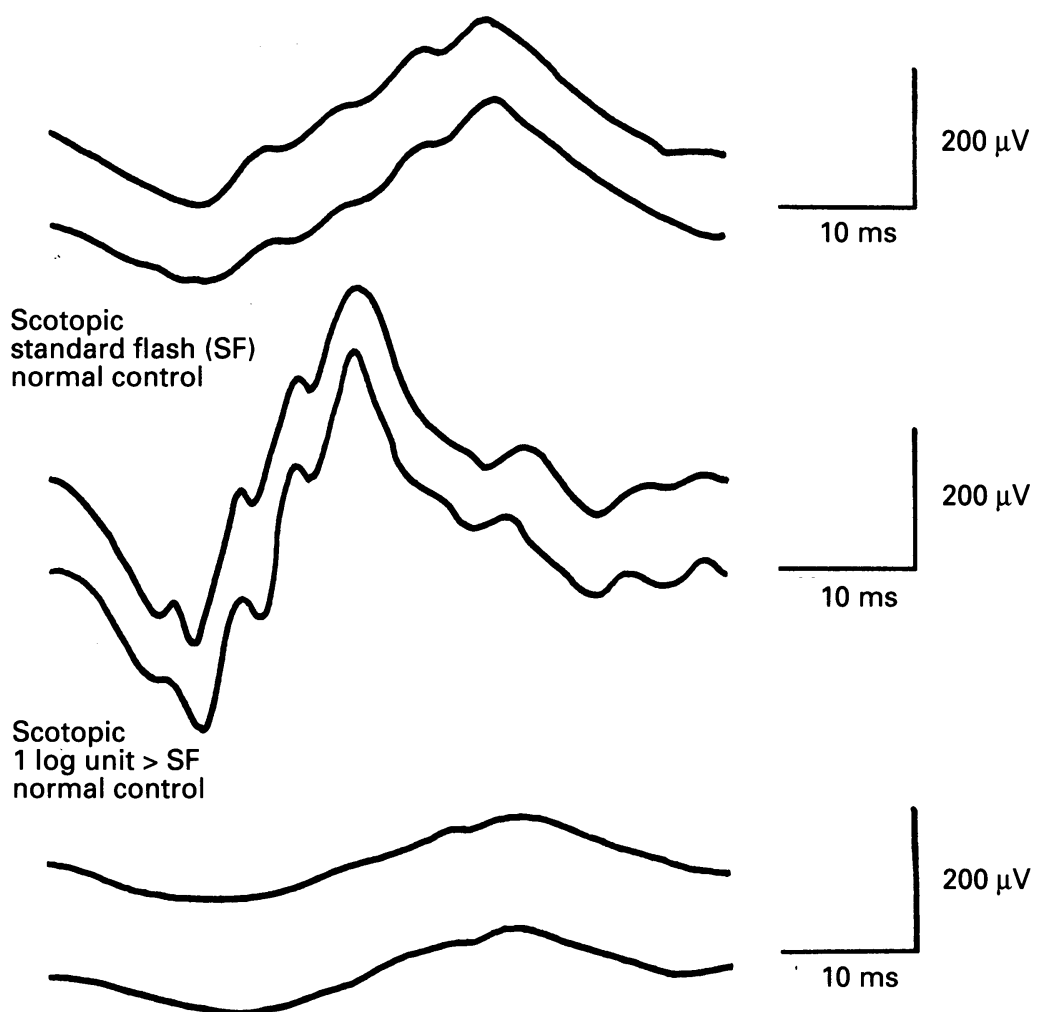

Scotopic SF

affected male

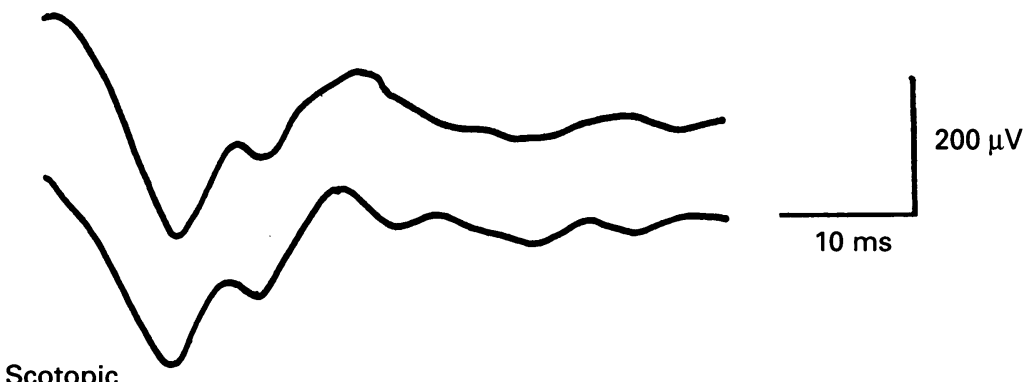

Scotopic

1 log unit $>$ SF

affected male

Figure 2 ERG of affected male (patient No 32) showing Schubert Bornsheim waveform with rod/cone separation of scotopic b-wave.
Electrophysiological examination shows affected individuals to have defective dark adaptation, with reduced scotopic b-wave amplitude on electroretinograms (ERG) (Schubert Bornschein type) with preserved oscillatory potentials. ${ }^{1}$ Carlson $^{6}$ reported a family in which affected males demonstrate greater reduction in b-wave amplitude in the $\mathrm{rod} /$ cone responses, and suggests that this is a separate, but AIED related, condition.

Linkage was first made to the $\mathrm{Xg}$ blood group. ${ }^{7}$ More recently, demonstrations of linkage between AIED and pericentromeric markers on the $\mathrm{X}$ chromosome ${ }^{89}$ call into question the earlier assignment of this disease to $\mathrm{Xp} 21.3-\mathrm{p} 21.1$ by Pillers, ${ }^{10}$ unless there is genetic heterogeneity in this condition.

CONGENITAL STATIONARY NIGHTBLINDNESS

Congenital stationary nightblindness (CSNB) is a group of disorders that can be divided into conditions with and without abnormal fundal appearance. The former group can be excluded by fundal examination and will not be considered here.

CSNB with normal fundi can be further classified: group A (Riggs type) CSNB is usually inherited in an autosomal dominant manner and the scotopic ERG is characteristically absent. Group B includes those conditions usually inherited in either autosomal recessive or X linked manner, and is characterised by a negative or Schubert Bornschein type ERG.

Miyake $^{11}$ (see Fig 1) classifies negative ERG CSNB on the basis of electrodiagnostic evaluation into (i) complete, and (ii) incomplete CSNB, that he suggests are two distinct entities (this view has been opposed by Pearce $^{12}$ ).

(i) Complete CSNB (CSNB1) in which the photopic (rod/cone) ERG is normal, and the 

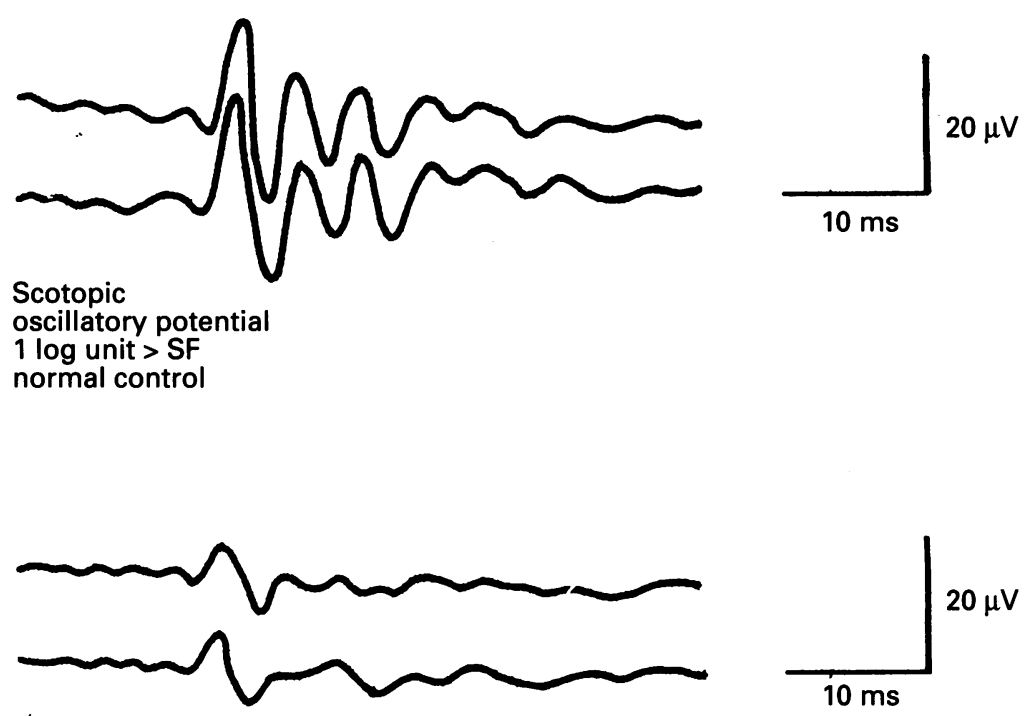

Scotopic

oscillatory potential

1 log unit > SF

affected male
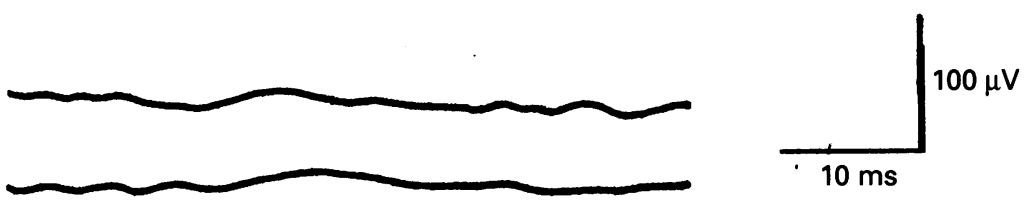

Photopic

affected male

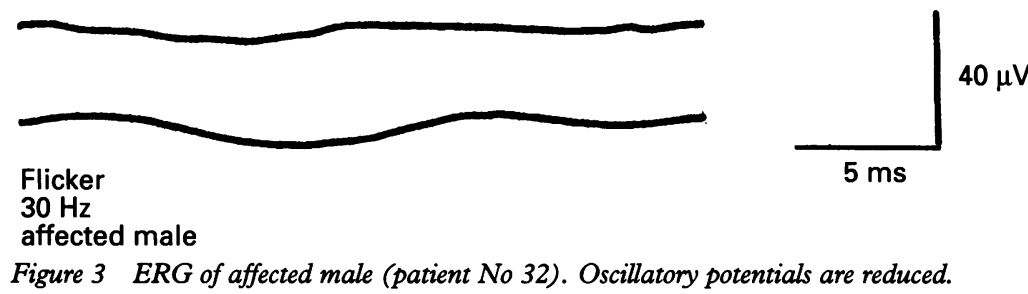

flicker (cone) ERG may be either normal or slightly subnormal.

(ii) Incomplete CSNB (CSNB2) in which the photopic and flicker (cone) ERGs are both grossly reduced. Miyake reported preserved oscillatory potentials occurring more commonly in this group than in complete CSNB.

The clinical features of $\mathrm{X}$ linked CSNB are very variable ${ }^{13}$ and affected males do not always manifest all of these. Nystagmus is usual, with visual acuity often subnormal. Refractive errors are common with ranges from -1.00 to -6.00 , and -12.00 to -20.00 dioptres, although hypermetropia has been reported. ${ }^{13} 14 \mathrm{X}$ linked myopia has also been reported. ${ }^{15}$ Khouri $^{14}$ suggested that myopia and CSNB are two traits. In the literature, a distinction has not always been made between CSNB1 and CSNB2, but there is a suggestion that myopia occurs more frequently in the complete form. Nightblindness is not always present. ${ }^{16}$ Optic disc anomalies $^{17}$ and strabismus ${ }^{13}$ have also been reported.

Carrier females are usually normal ${ }^{18-20}$ but Pearce $^{13}$ and Ruttum ${ }^{21}$ report manifesting females, and Miyake ${ }^{22}$ found reduced ERG oscillatory potentials in obligate carriers.

$\mathrm{X}$ linked incomplete CSNB has been shown to map to the proximal short arm of the $\mathrm{X}$ chromosome, 8182023 although the series by Mussarella ${ }^{23}$ included both complete and incomplete forms.

It is apparent that the clinical and electrophysiological characteristics of AIED and incomplete $\mathrm{X}$ linked CSNB are very similar. Several authors have suggested that the two diagnoses represent a single entity. ${ }^{82-26}$

\section{Materials and methods}

\section{FAMILY STUDIES}

This is a large family, which has lived in Cardiff and the Vale of Glamorgan for several generations. Of the 57 family members known to us, we obtained blood from 29 , and 20 permitted a clinical ophthalmic examination to be performed in their homes.

Clinical assessment was performed by one of us (NH), and entailed the following: ophthalmic history (including questioning for symptoms of nightblindness), measurement of Snellen visual acuity, refraction, colour vision assessment using Ishihara charts, ocular motility examination slit-lamp examination, direct and indirect ophthalmoscopy.

The family structure is shown in Figure 1 and the clinical findings in Table 1. Blood samples were collected with informed consent and permission of the local research ethics committee.

\section{ELECTROPHYSIOLOGICAL ASSESSMENT}

Two members of the family (affected male No 32 and the manifesting female carrier No 14) agreed to undergo electrophysiological test: ERG (scotopic, photopic, and flicker) and VER.

ERGs were performed using a Ganzfield stimulator and Nicolet C4 clinical averager. With pupils dilated, a Burien-Allen contact lens electrode was placed on the cornea and referenced to an outer canthal skin electrode. The scotopic ERGs were obtained following 20 minutes of dark adaptation. Two stimulus intensities were then used: one was our 'standard flash' (SF) of 1.8 foot lamberts (FL), and this was followed by a stimulus increased to $1 \log$ unit brighter than the SF. Stimuli were presented at 10 second intervals, and four averages obtained.

Photopic ERGs were obtained following light adaptation of 35 FL for 10 minutes using a $1 \log$ unit greater than SF stimulus. Flicker (cone) ERGs were performed using a $30 \mathrm{~Hz}$ stimulus of $0.25 \mathrm{log}$ units greater than SF against a background of $25 \mathrm{FL}$. Oscillatory potentials were analysed under scotopic conditions following online digital filtering of 100-1000 Hz.

Peak to peak amplitude measurement of a- and b-waves was made for each stimulus paradigm, together with measurement of scotopic oscillatory potentials 1-4. Note was also made of the presence or absence of a rod/cone separation of the scotopic b-wave. 


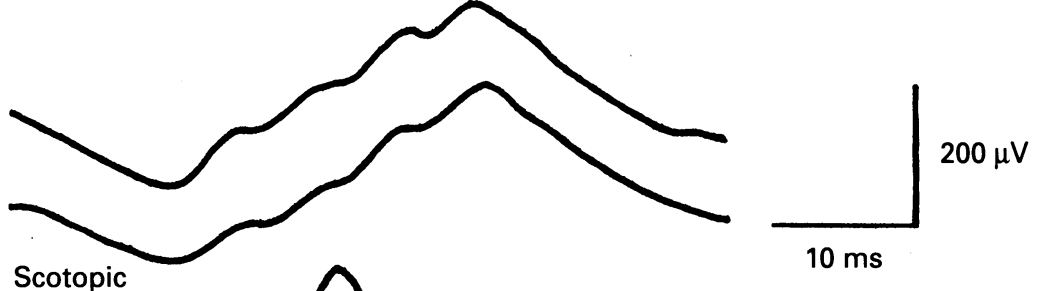

Scotopic standard flash (SF) normal control

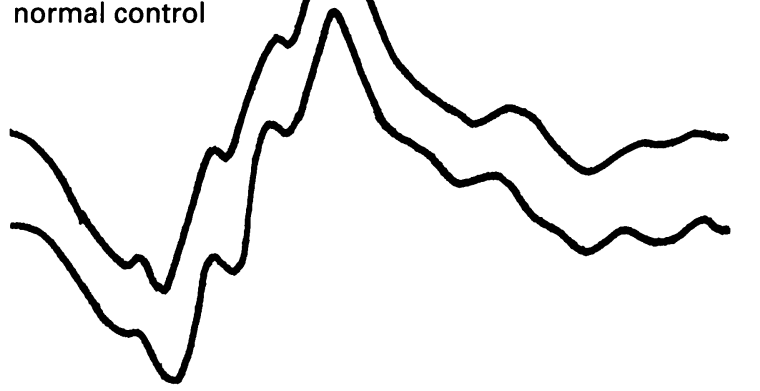

Scotopic

1 log unit > SF

normal control

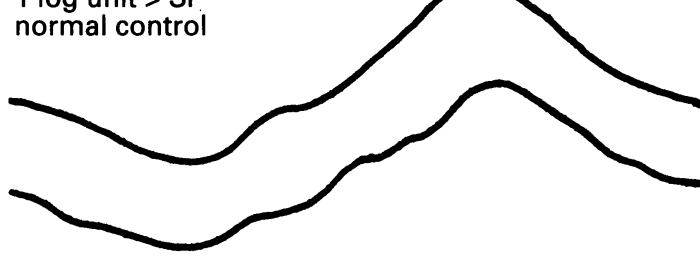

Scotopic SF

manifesting female
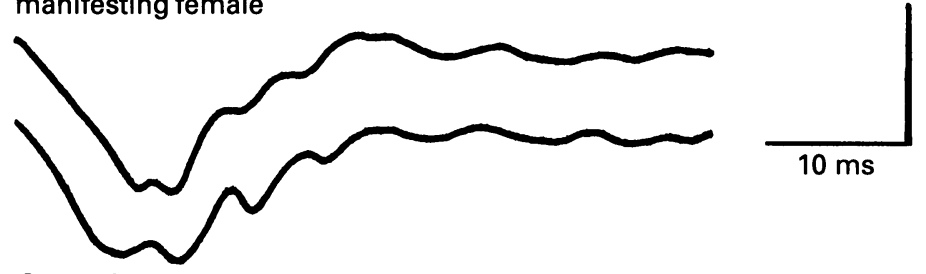

$10 \mathrm{~ms}$

$200 \mu \mathrm{V}$
Scotopic

1 log unit > SF

manifesting female

Figure 4 ERG of manifesting female carrier (patient No 14) showing a partial Schubert Bornsheim response under scotopic conditions.

Visually evoked responses (VERs) were performed to both flash and pattern stimulation using the Apkerian technique ${ }^{27}$ to identify any misrouting of the visual pathways.

These individuals underwent more extensive colour vision analysis using the Farnsworth 100 hue test.

Goldmann Weekers dark adaptometry was performed over a period of 30 minutes, recordings being made every 90 seconds.

\section{Results}

\section{CLINICAL FINDINGS}

Nightblindness symptoms were found in two manifesting males, and a manifesting female carrier. All others denied such symptoms.

Photophobia was a symptom for one manifesting male and three other males.

Reduced visual acuity (VA) was a common finding, but in several cases this could be explained by strabismic or anisometropic amblyopia. Reduced VA without amblyopia was found in all manifesting males and at least one of the other males. Marked reduction in VA was found in the manifesting female.

Refractive error was present in all but two of the family members examined. The range of error was from +6.50 DS to $-18.00 \mathrm{DS}$. Astigmatism greater than $1.50 \mathrm{DC}$ was only found in patient No 14, the manifesting female, and No 29, a female of uncertain status.

Manifest strabismus was present in six cases. In cases $30,33,35,47$, and 49 it was accommodative, secondary to hypermetropia.

Amblyopia was present in four cases of accommodative strabismus. A further two cases occurred in association with anisometropia. Case 14 may have meridional amblyopia because of high astigmatism.

Nystagmus was manifest in four of the affected males and the manifesting female carrier. Male No 27, who gave photophobia as a symptom and wore glasses for low hypermetropia, exhibited a marked degree of physiological nystagmus.

Colour vision was normal except in two manifesting males who demonstrated a mild $\mathrm{red} / \mathrm{green}$ defect.

Ocular pigmentation was noted to be reduced in three of the manifesting males, case 40 having very blond hair and pale blue irides along with the reduced pigmentation of the retinal pigment epithelium (RPE). The manifesting obligate carrier female was also noted to have a pale fundus. No cases exhibited iris transillumination. All other members examined had darker complexions with brown hair.

Disc anomalies were found in seven cases. These included hypoplastic or tilted optic discs (males 24, 28, 32, and 40), and asymmetry of the cup/disc ratios (with normal intraocular pressure and no glaucomatous features of the disc) in cases 30 and 33. A tripartite division of the retinal vessels was noted at the small optic disc in the more hypermetropic eye of case 17 .

Therefore, of 20 family members examined, five males and an obligate female carrier were manifesting for the condition and could be diagnosed as likely AIED or incomplete CSNB. A further three males had photophobia and hypermetropia, with two of these having mildly reduced VA. One of these also exhibited a disc anomaly and strabismus.

Apart from the manifesting female, other carriers had normal vision in at least one eye. All obligate carriers were found to be hypermetropic, three having amblyopia as a result of strabismus, anisometropia or both, with two of the three having a disc anomaly.

Four females had either unilateral or bilateral hypermetropia, two cases having strabismus that was associated with amblyopia in one. Amblyopia was also found in one of the cases with marked anisometropia and astigmatism in the hypermetropic eye. These females may well be manifesting female carriers.

No patients were found to have either iris transillumination defects or abnormal areas of skin pigmentation. 


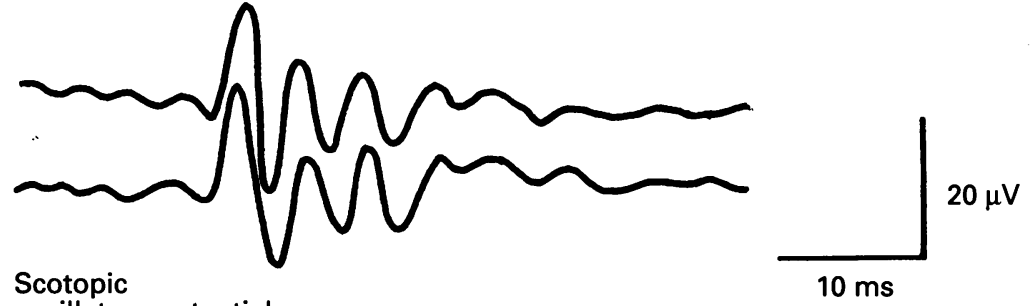

Scotopic

oscillatory potential

1 log unit > SF

normal control

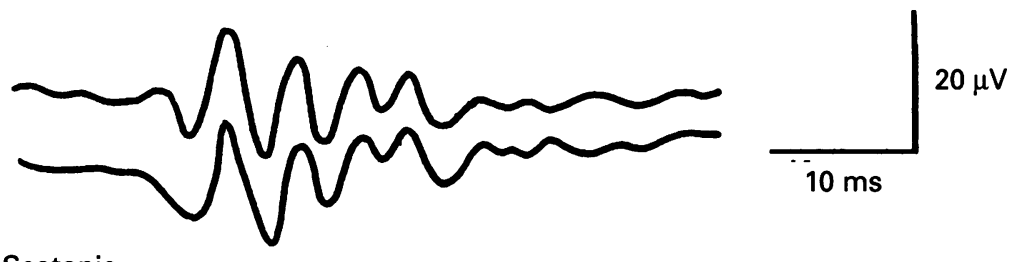

Scotopic

oscillatory potential

1 log unit > SF

manifesting female
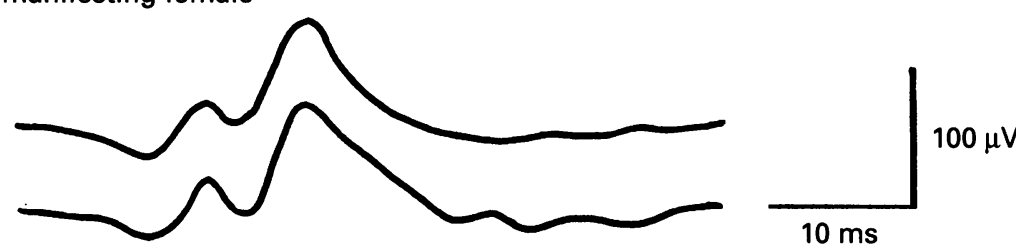

Photopic

manifesting female

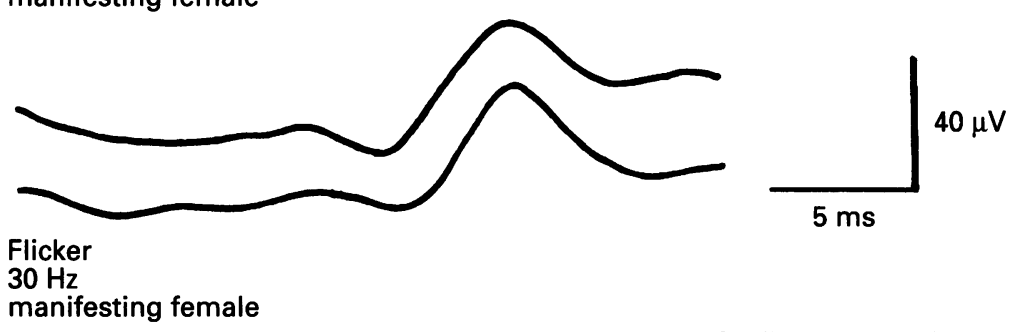

Figure 5 ERG of manifesting female carrier (patient No 14). Oscillatory potentials are well preserved, and photopic and ficker ERGs are normal.

electrophysiological examination: an affected male (No 32) and the fully manifesting female obligate carrier (No 14).

Patient No 32 (affected male) (Figs 2 and 3)

(a) Scotopic ERG standard flash: slightly reduced a- and b-waves $(42 \mu \mathrm{V}$ and $112 \mu \mathrm{V}$ right, $46 \mu \mathrm{V}$ and $119 \mu \mathrm{V}$ left respectively). Laboratory normals: a-wave $51-86 \mu \mathrm{V}$, b-wave $165-340 \mu \mathrm{V}$.

(b) Scotopic ERG (1 log unit $>$ SF): normal a-wave $(210 \mu \mathrm{V}$ right, $180 \mu \mathrm{V}$ left). Reduced b-wave $(152 \mu \mathrm{V}$ right, $160 \mu \mathrm{V}$ left). This is a Schubert Bornsheim type ERG with rod/cone separation of the b-wave. Oscillatory potentials are grossly reduced.

Photopic ERG: grossly reduced a- and b-waves right and left $(<5 \mu \mathrm{V})$.

Flicker (cone) ERG: grossly reduced right and left $(<5 \mu \mathrm{V})$.

Laboratory normals ( $1 \log$ unit $>S F$ ):

Scotopic ERG: a-wave 160-320 $\mu \mathrm{V}$,

b-wave $280-650 \mu \mathrm{V}$.

Photopic ERG: b-wave $62-150 \mu \mathrm{V}$.

Flicker ERG: b-wave 35-110 $\mu \mathrm{V}$.

VER: reduced major components but symmetrical between hemispheres on stimulation of either eye.
Dark adaptation: normal cone threshold but rod threshold elevated by $2 \cdot 2 \log$ units.

Patient No 14 (manifesting female carrier)

(Figs 4 and 5)

(a) Scotopic ERG (standard flash) normal a- and b-waves $(80 \mu \mathrm{V}$ and $205 \mu \mathrm{V}$ right, $77 \mu \mathrm{V}$ and $210 \mu \mathrm{V}$ left respectively).

(b) Scotopic ERG (1 log unit >SF): the scotopic b-waves are reduced from both eyes (190 $\mu \mathrm{V}$ right, $208 \mu \mathrm{V}$ left). The a-waves are normal $(185 \mu \mathrm{V}$ right, $190 \mu \mathrm{V}$ left). This is clear rod/cone separation of the scotopic b-waves and well preserved oscillatory potentials. These ERGs have a partial Schubert Bornsheim appearance.

Photopic ERG: normal both eyes (a-waves: $70 \mu \mathrm{V}$ right, $61 \mu \mathrm{V}$ left) (b-waves: $150 \mu \mathrm{V}$ right, $120 \mu \mathrm{V}$ left).

Flicker (cone) ERG: normal both eyes (b waves: $30 \mu \mathrm{V}$ right, $34 \mu \mathrm{V}$ left).

VER: normal amplitude and symmetry.

Dark adaptation: normal cone threshold, but the rod threshold was elevated by 1.4 log units.

\section{Discussion}

There are three recognised eye conditions which map to $\mathrm{Xp}$ and in which nystagmus frequently occurs. These are the NettleshipFalls syndrome of ocular albinism, CSNB, and AIED. The Nettleship-Falls syndrome is not likely for this family because it maps more distally (Xp22.3) than the gene locus suggested by our linkage analysis and no family members have demonstrable iris transillumination. Also there is absence of misrouting of the optic pathways on VERs as expected in NettleshipFalls syndrome. The carrier females in this family have subnormal acuity, and hypopigmented skin macules and absent foveal reflexes have not been recorded.

Complete CSNB was excluded on the basis of Miyake's classification of ERG findings. ${ }^{12}$ The mapping of CSNB to Xp in some studies could refer to the complete form, as some studies have not differentiated between the two forms. This would be consistent with the linkage study findings in the Welsh family.

The eye disorder in this family segregates as a sex linked trait with some manifestation in female carriers. Given that all obligate carrier females examined showed marked hypermetropia, it is probable that this is a feature of the sex linked gene defect in this family. It is therefore likely that the males who showed marked hypermetropia are also affected by this gene defect. The female who showed unilateral hypermetropia, with myopia in the other eye, may also be a carrier who is manifesting the defect in a mild form because of a more favourable pattern of $\mathrm{X}$ chromosome inactivation. The molecular genetic studies and genetic linkage analyses carried out is being prepared for a more detailed report (Headland $\mathrm{S}$, in preparation). However, the principal finding is the absence of recombination between the AIED/(CSNB2) condition and the pericentromeric marker M27 $\beta$ (DXS255), 
Scotopic

Photopic
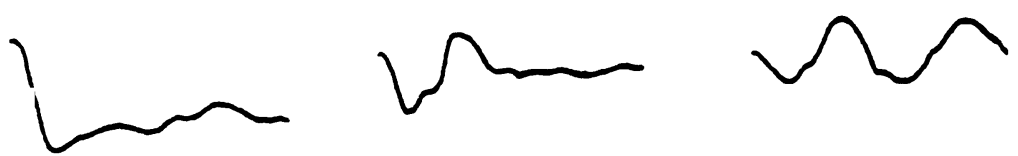

CSNB1 (Miyake)
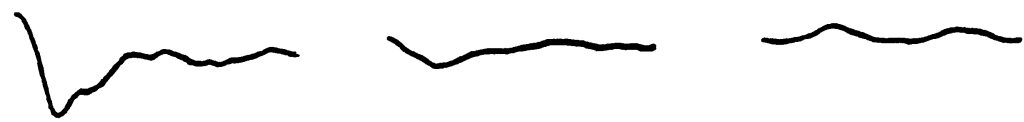

CSNB2 (Miyake)

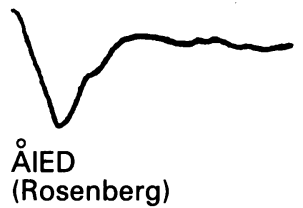

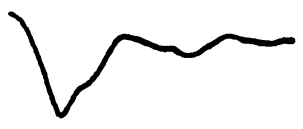

CSNB2/ÅlED

(This study)

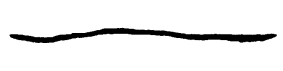

$100 \mu \mathrm{V}$

$50 \mathrm{~ms}$

Figure 6 Comparison between published ERG findings of Miyake (CSNB1, CSNB2), Rosenberg (AIED), and our study.

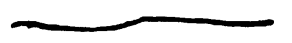

At present, it is not known whether nightblindness and refractive error are caused by an alteration in the same gene, or whether they result from two tightly linked but non-allelic mutations. In one report, ${ }^{15}$ a family in which three of five affected members were hypermetropic instead of myopic, had refractive errors ranging from $+1 \cdot 75$ to $+4 \cdot 25$ dioptres. Hence, hypermetropia can occur in affected males with CSNB. Carlson ${ }^{7}$ also reports a family with an AIED-related condition in which only three out of five males were myopic.

Khouri ${ }^{15}$ proposes that two genes are responsible for this variability of phenotype. The two genes are both $\mathrm{X}$ linked and crossing over between these could account for cases of CSNB without myopia. It is possible that nightblindness and myopia are inherited separately. Support for this hypothesis is that $\mathrm{X}$ linked myopia (without nightblindness) is a well recognised genetic entity. ${ }^{16}$

Pearce $^{13}$ believes that there is a single mutant gene responsible for the phenotypic differences seen in this condition. This theory is rationalised as follows.

In CSNB2 there is neural dysfunction in the retina between photoreceptors and bipolar cells. In photopic function this disturbance is illustrated by differences in visual acuity, nystagmus, visual fields, and cone dysfunction. In scotopic function it is illustrated by differences in night vision and rod dysfunction.

In our study of the literature, we found the clinical features of AIED and CSNB2 to be very similar. Genetic linkage data from several studies 910192126 suggest a locus for AIED or CSNB2 on the proximal portion of the short arm of the $\mathrm{X}$ chromosome, or the pericentromeric region. The clinical findings and linkage results in this family from South Glamorgan are very similar to both conditions, and we support the proposal of several previous authors that the two conditions, incomplete CSNB (CSNB2) and AIED, are the same entity. ${ }^{392526}$

This work was presented at the IX meeting of the International Society for Genetic Eye Diseases, Siena, Italy, on 2 June 1992. We thank Glaxo for funding this work as part of a BMedSc Medical Genetics Project. this is the first time, to our knowledge, that a reduced scotopic b-wave has been reported in a carrier female in either condition.

Interestingly, the ERG findings in AIED are very similar to those found in complete CSNB ${ }^{2}$ (see Fig 6). They support the proposition, first forwarded by Krill, ${ }^{25}$ and later by Weleber ${ }^{3}$ that AIED and incomplete CSNB are the same condition since clinical findings and linkage data are also very similar. AIED is not a true form of ocular albinism since ocular hypopigmentation is variable, macromelanosomes or immature melanosomes are not seen on skin biopsy, and albino misrouting is not present. ${ }^{5}$ Perhaps, as Weleber suggests, it should be classified as an incomplete form of CSNB.

Our family gives both clinical and linkage data according to that described for both conditions, and with the support of the ERG findings we conclude that either AIED or incomplete $\mathrm{X}$ linked CSNB (CSNB2) is the diagnosis in this family.
1 Forsius H, Eriksson AW. Ein Neues Augensyndrom mit X-chromosomaler Transmission. Klin Monatsbl Augenheilkd 1964; 144: 447-57.

2 Rosenberg T, Schwartz M, Simonsen SE. Åland eye disease (Forsius Eriksson Miyake syndrome) with probability established in a Danish family. Acta Ophthalmol 1990; 68 281-91.

3 Weleber RG, Pillers DM, Powell BR, Hanna CE, Magenis $\mathrm{RE}$, Buist NRM. Åland Island eye disease (ForsiusEriksson syndrome) associated with contiguous deletion syndrome at Xp21. Arch Ophthalmol 1989; 107: 1171-9. 'Donnell FE, Hambrick GW, Green WR, Iliff WJ, Stone WL. X-linked ocular albinism: an oculocutaneous macromelanosomal disorder. Arch Ophthalmol 1976; 94 1883-92.

5 van Dorp DB, Eriksson AW, Delleman JW, van Vliet AG, Collewijn H, van Balen ATM, et al. Åland eye disease - no albino misrouting. Clin Genet 1985; 28: 526-31.

6 Creel D, O'Donnell FE Jr, Witkop CJ. Visual system anomalies in human ocular albinos. Science 1978; 201: 931.

7 Carlson S, Vesti E, Raitta C, Donner M, Erksson AW, Forsius $\mathrm{H}$. Clinical and electroretinographic comparison between Åland Island eye disease and a newly found related disease with X-chromosomal inheritance. Acta Ophthalmol 1991; 69: 703-10.

8 Sanger $\mathrm{R}$. Genes on the $\mathrm{X}$ chromosome; the human $\mathrm{X}$ RE, Buist NRM. Aland Island eye disease (Forsius 
chromosome. Symposium of the Genetic Society of Canada. Canad F Genet Cytol 1965; 7: 179-88.

9 Glass IA, Good P, Coleman MP, Fullwood P, Giles MG Lindsay $S$, et al. Genetic mapping of a cone and rod dysfunction ( $\AA$ land Island eye disease) to the proximal shor arm of the human X chromosome. F Med Genet 1993; 30 $1044-50$

10 Alitalo T, Kruse TA, Forsius $H$, Eriksson AW, de la Chapelle A. Localisation of the Alland Island eye disease locus to the pericentromeric region of the $\mathrm{X}$ chromosome by linkage analysis. Am $\mathcal{F}$ Hum Genet 1991 ; 48: 31-8.

11 Pillers DM, Towbin JA, Chamberlain JS, Wu D, Rainer J, Powell BR, et al. Deletion mapping of Åland Island eye disease to Xp21 between DXS67 (B24) and Duchenne muscular dystrophy. Am $\mathcal{f}$ Med Genet 1990; 47: muscular

12 Miyake Y, Yagasaki K, Horiguchi M, Kawase Y, Kanada T. Congenital stationary nightblindness with negative ERG: a new classification. Arch Ophthalmol 1986; 104 1013-20.

13 Pearce WG. Gene locus for X-linked congenital stationary night-blindness. Genomics 1990; 8: 743-4.

14 Pearce WG, Reedyk M, Coupland SG. Variable expressivity in X-linked congenital stationary night-blindness. Can Ophthalmol 1990; 25: 3-10.

15 Khouri G, Mets MB, Smith VC, Wendell M, Pass AS $\mathrm{X}$-linked congenital stationary nightblindness: review and a report of a family with hypermetropia. Arch Ophthalmol a report of a family with

16 Bartsocas CS, Kastranta $\mathrm{AD}$. X-linked form of myopia. Hum Hered 1981; 31: 199-200.

17 Price MJ, Judisch GF, Thompson HS. X-linked congenital stationary nightblindness with myopia and nystagmus without complaint of nyctalopia. $\mathcal{f}$ Pediatr Ophthalmo Strabismus 1988; 25: 33-6.
18 Heckenlively JR, Martin DA, Rosenbaum AL. Loss of electroretinographic oscillatory potentials, optic atrophy, and dysplasia in congenital stationary nightblindness. Am $\mathcal{F}$ dysplasia in congenital stationary nightblindness. Am $\mathcal{F}$
Ophthalmol 1983;96: 526-34.

19 Gal A, Schinzel A, Orth U, Frazer N, Mollica F, Craig IW, et al. Gene of X-chromosomal congenital stationary
nightblindness is closely linked to DXS7 on Xp. Hum nightblindness is closely

20 Lachapelle P, Little JM, Polomeno RC. The photopic electroretinogram in congenital stationary nightblindness with myopia. Invest Ophthalmol 1983; 96: 526.

21 Bech-Hansen NT, Field LL, Schramm AM, Reedyk M, Pearce WG. Regional localisation of the locus for $\mathrm{X}$-linked congenital stationary night-blindness. [Abstract.] Cytogenet Cell Genet 1989; 51: 959.

22 Rutum MS J females in X-linked congenital stationary night-blindness. Ophthalmology 1992; 99: 747-52.

23 Miyake Y, Kawase Y. Reduced amplitude of oscillatory potentials in female carriers of $\mathrm{X}$-linked congenital stationary nightblindness. Am $\mathcal{f}$ Ophthalmol 1984; 98: 208-15.

24 Musarella MA, Weleber RG, Murphey WH, Young RS, Anson-Cartwright L, Mets M, et al. Assignment of the gene for complete congenital stationary nightblindness (CSNB1) to human chromosome Xp11.3. Genomics 1989; 5: 727-37.

25 Krill AE. Congenital stationary night-blindness. In: Krill AE, ed. Krill's hereditary and choroidal diseases. New York: $\mathrm{AE}$, ed. Krill's hereditary and choroidal diseases. New York: 26 Schwartz M, Rosenberg T. Alland eye disease: linkage data. Genomics 1991; 10: 327-32.

27 Apkerian P, Reits D, Spekreijse H, van Dorp D. A decisive electrophysiological test for human albinism. Electroenceph Clin Neurophysiol 1983; 55: 513-31. 